\title{
Symposium at the 26th Annual Meeting of the Japan Society of Human Genetics, 1981: Genetic Markers in Blood
}

\section{Genetic Markers}

by Dr. Susumu Shibata

Erythrocyte blood group systems may be cited as representative prototypes of genetic markers, that have been studied extensively. The human leukocyte antigen (HLA) system, which is now studied with keen interest, is developing into one of the most important genetic markers. Both the blood groups and the HLA constitute critical factors for the success of blood transfusion and tissue transplantation. However, the majority of genetic markers, with exception of blood groups and HLA, are enzymes or other proteins of tissues and blood plasma which were discovered and identified largely by the development of electrophoretic and chromatographic techniques. They are highly evaluated tools for the recognition of human individuality and the study of human polymorphisms.

It is, of course, unavoidable that not all genetic markers can be discussed with equal emphasis and therefore we have adjusted the focus of the selection of subjects to those enzymes and other protein systems of blood serum and erythrocytes in which the members of the Japan Society of Human Genetics have been specially interested and have, so far, made notable contributions.

In this symposium we arranged the following 5 themes: (1) genetic markers of the complement system, (2) HLA (in relation to the function of lymphocytes), (3) pseudocholinesterase of serum and its variants, (4) some erythrocyte enzymes, and (5) a biochemical genetic survey of certain erythrocyte enzymes and other proteins in blood samples obtained from selected populations in Hiroshima and Nagasaki. Supplemental observation on genetic polymorphisms in Aichi Prefecture are also presented. We hope that this symposium will awaken the interest of those attending this meeting. Thank you. 



\title{
GENETIC POLYMORPHISMS OF COMPLEMENT SYSTEMS IN JAPANESE
}

\author{
Keiichi Омото and Katsushi Tokunaga
}

Department of Anthropology, University of Tokyo, Tokyo 113, Japan

\begin{abstract}
Recently, genetic polymorphisms were detected by electrophoretic methods in a number of human complement proteins: C2, C3, C4, C5, C6, C7, C8, Factor $\mathrm{B}(\mathrm{BF})$, Factor D and C1-inhibitor (See Alper and Rosen, 1976; Lachmann and Hobart, 1978; and Hobart et al., 1981 for C5 polymorphism). Some of these polymorphisms attracted special attention of investigators because of the discovery of associations between particular alleles and disseases, such as those between $\mathrm{C} 3^{*} \mathrm{~F}$ and rheumatoid arthritis (Farhud et al., 1972) or BF*F1 and the early-onset insulindependent diabetes mellitus (IDDM) (Raum et al., 1979; Kirk et al., 1979) on the one hand, and because of the linkage between $\mathrm{C} 2, \mathrm{C} 4$ and $\mathrm{BF}$ loci and the $\mathrm{MHC}$ loci on the short arm of the chromosome No. 6, on the other. Thus far, most studies have been confined to the European racial groups. In this review, we present the data mainly obtained in our laboratory concerning the polymorphisms of $\mathrm{BF}$ and $\mathrm{C} 2$ in Japanese with special reference to the distribution of the variant types, linkage disequilibrium with alleles of HLA loci, and some evidences of disease associations. Also the present status of typing of $\mathrm{C} 3$ and $\mathrm{C} 4$ in Japan is briefly mentioned.
\end{abstract}

\section{C3 polymorphism}

Using fresh sera, this polymorphism is easily shown by protein stain after agarose gel electrophoresis. It is known that a "fast" variant of C3 has an appreciable frequency in Japanese: 12 out of 464 samples (Tokyo) in one study (Harada et al., 1975) and 9 out of 1,092 samples (Kyoto) in another study (Nishimukai et al., 1979) were found to be heterozygous for this variant. In our preliminary study (Tokyo), 8 samples among 525 were found to be heterozygous for a fast $\mathrm{C} 3$ variant. It is likely that this variant is not identical to the $\mathrm{C} 3 \mathrm{~F}$ variant commonly found in Europeans. We recently examined $\mathrm{C} 3$ types of sera from 113 patients with rheumatoid arthritis and found no evidence for an elevated incidence of the variant C3 types (unpublished).

\section{Factor $B(B F)$ polymorphism}

$\mathrm{BF}$ polymorphism is usually examined by an agarose gel electrophoresis followed by immunofixation (Alper et al., 1972). In addition to a pair of common alleles $\left(B F^{*} F\right.$ and $B F^{*} S$ ), two relatively uncommon alleles $B F^{*} F 1$ and $B F^{*} S 0.7$ are 
Table 1. Distribution of $\mathrm{BF}$ allele frequencies in various populations.

\begin{tabular}{|c|c|c|c|c|c|c|c|}
\hline \multirow[b]{2}{*}{ Populations } & \multirow[b]{2}{*}{$\mathrm{N}$} & \multicolumn{5}{|c|}{ BF Alleles } & \multirow[b]{2}{*}{ Authors } \\
\hline & & $\mathbf{S}$ & $\mathrm{F}$ & $F 1$ & $\begin{array}{c}\text { S1 } \\
\text { (S0.7) }\end{array}$ & Others a & \\
\hline \multicolumn{8}{|l|}{ Caucasoid } \\
\hline USA Caucasian & 158 & .709 & .278 & - & .013 & - & Alper et al., 1972 \\
\hline West German & 1,245 & .808 & .174 & .008 & .009 & 1 & Mauff et al., 1975 \\
\hline French & 247 & .757 & .219 & .010 & .014 & - & Hauptmann et al., 1976 \\
\hline Norwegian & 300 & .817 & .172 & .005 & .007 & - & Teisberg \& Olaisen 1977 \\
\hline Swiss & 654 & .805 & .176 & .010 & .009 & - & Scherz et al., 1977 \\
\hline Italian & 62 & .718 & .250 & .008 & .024 & - & Scherz et al., 1977 \\
\hline Dane & 318 & .780 & .203 & .008 & .009 & - & Mortensen \& Lamm 1981 \\
\hline Spaniard & 330 & .658 & .266 & .052 & .022 & - & Rodriguez-Córdoba et al., 1981 \\
\hline French Basque & 201 & .550 & .296 & .015 & .139 & - & Ohayon et al., 1980 \\
\hline Australian Caucasian & 470 & .797 & .187 & .010 & .006 & - & Stewart et al., 1979 \\
\hline \multicolumn{8}{|l|}{ Non-Caucasoid } \\
\hline Lapps & 197 & .888 & .112 & 0 & 0 & 0 & Teisberg \& Olaisen 1977 \\
\hline USA Oriental & 86 & .890 & .110 & 0 & 0 & 0 & Alper et al., 1972 \\
\hline Japanese & 360 & .824 & .176 & 0 & 0 & 0 & Horai 1976 \\
\hline Japanese & 487 & .801 & .198 & 0 & 0 & 1 & Tokunaga et al., 1981a \\
\hline USA Negroid & 127 & .437 & .512 & .051 & 0 & 0 & Alper et al., 1972 \\
\hline South African Negroes & 944 & 282 & .655 & .034 & .025 & 7 & Mauff et al., 1976 \\
\hline S.A. Indian & 90 & .645 & .322 & 0 & .033 & 0 & Mauff et al., 1976 \\
\hline
\end{tabular}

a Observed number of variant phenotypes.

known in European populations. $B F^{*} F 1$ determines the $\mathrm{BF}$ component migrating faster than $B F F$ and its frequency is known to be higher in southern Europe than in northern Europe (Table 1). It is this allele that shows an association with IDDM (Raum et al., 1979; Kirk et al., 1979).

Horai (1976) was the first to report BF allele frequency in Japanese, but no variant phenotype other than the three common phenotypes ( $S, S F$ and $F$ ) were found among 360 healthy donors in Nara Prefecture. Recently, we detected a BF variant similar but not identical to BF F1 type (Tokunaga et al., 1981a). It migrates slightly slower than $\mathrm{BF} F 1$ and the conversion product $\mathrm{Bb}$ after zymosan treatment shows a distinct band (Fig. 1). The variant allele was denoted $B F^{*} F T$ (F Tokyo). In a sample from 65 IDDM patients of Tokyo Women's Medical College, two samples were found to be heterozygous for this variant: one BF FFT and the other BF SFT. In a control sample of 491 unrelated healthy individuals, the variant was encountered only once. Thus, the incidence of the BF FT positive phenotypes was shown to be significantly elevated in IDDM patient group $(\mathrm{p}<0.05)$ (Tokunaga 


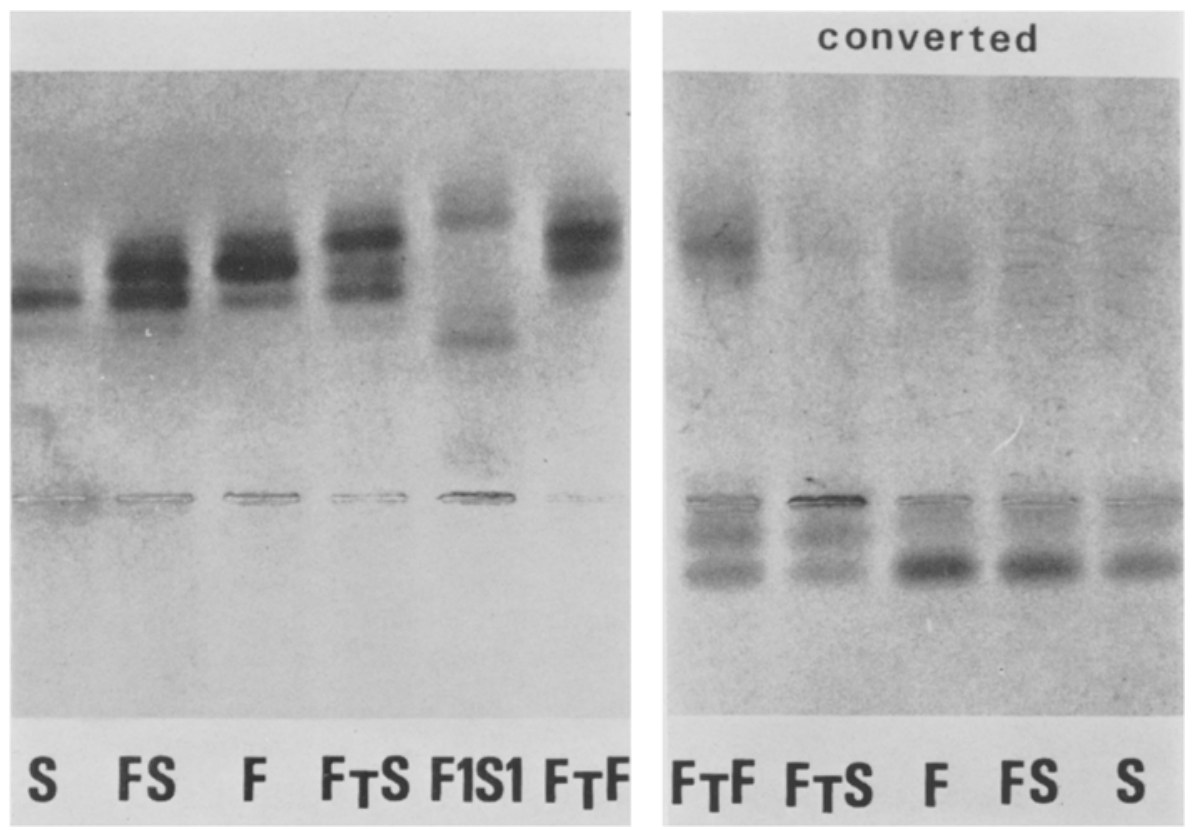

Fig. 1. Photographs showing a a arose gel electrophoretic patterns of various BF phenotypes. To the right, the conversion fragments after zymosan treatment are shown.

Table 2. BF types observed among 108 IDDM patients in Japan. Data of controls is taken from Tokunaga et al., 1981 b.

\begin{tabular}{lrrc}
\hline & $\begin{array}{c}\text { Patients } \\
(\mathrm{n}=108)\end{array}$ & $\begin{array}{c}\text { Controls } \\
(\mathrm{n}=496)\end{array}$ & $\mathrm{p}$ \\
\hline BF + & $103(95.4 \%)$ & $473(95.4 \%)$ & NS \\
BF F + & $33(30.6 \%)$ & $176(35.5 \%)$ & NS \\
BF FT + & $3(2.8 \%)$ & $1(0.2 \%)$ & $<0.025^{\mathrm{a}}$ \\
\hline
\end{tabular}

2 $\mathrm{RR}=14.1$

et al., 1981a). More recently, BF typing was carried out on 43 IDDM patients of Toranomon Hospital, Tokyo, revealing a further BF FT positive individual (unpublished data). This resulted in the total incidence of $2.8 \%$ BF FT positive phenotypes in IDDM patients in contrast to $0.2 \%$ in controls (Table 2). It is interesting that association of a rare BF variant and IDDM is found in different racial groups (Southern European and Japanese) but the variant BF alleles involved. in this association are not identical between two racial groups. BF typing was also carried out in a sample from 123 patients of rheumatoid arthritis. BF FTS phenotype was observed once, showing no statistically significant increase of the variant. 


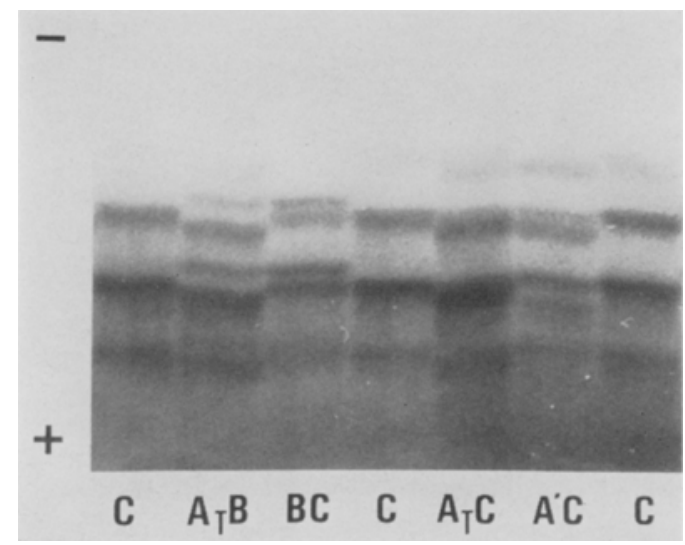

Fig. 2. Photograph showing the isoelectrofocusing patterns of various $\mathrm{C} 2$ phenotypes found in Japanese (Tokunaga et al., 1981b). Note that the bands corresponding to $\mathrm{C} 2 \mathrm{AT}$ show relatively more intense hemolytic activity.

We also studied associations between BF alleles and allele of HLA A, HLA B and HLA C (Tokunaga et al., 1982). The following associations were found to have significantly positive delta values and considered to be in linkage disequilibrium: $B F^{*} F-H L A A w 33(\mathrm{p}<0.0001), B F^{*} F-H L A B 17(\mathrm{p}<0.025), B F^{*} F-H L A$ $B 15(\mathrm{p}<0.025), B F^{*} F-H L A B w 44(\mathrm{p}<0.0001)$ and $B F^{*} F-H L A C w 3(\mathrm{p}<0.05)$. Among these associations, only the $B F^{*} F-H L A B w 44$ is known to be present in general European populations.

\section{C2 polymorphism}

Polymorphism of $\mathrm{C} 2$ was detected in our laboratory by isoelectrofocusing (pH 5-7 or 5-8) in polyacrylamide gel followed by visualization of $\mathrm{C} 2$ hemolytic bands with sensitized sheep erythrocytes in agarose overlay.

Relatively few studies on the distribution of $\mathrm{C} 2$ polymorphic types have been reported (Table 3). In Japanese, at least four alleles at the $\mathrm{C} 2$ locus seem to occur: $C 2^{*} C, C 2^{*} B, C 2^{*} A T$ and $C 2^{*} A^{\prime}$ (Fig. 2 and Table 4). $C 2^{*} A T$ and $C 2^{*} A^{\prime}$ are the variants not hitherto known in European populations (Tokunaga et al., 1981b). The results of simultaneous typing of HLA-A, -B, and -C specificities indicated the presence of significant associations of $C 2^{*} A T$ with $H L A-B 15(\mathrm{p}<0.0001)$ and with $H L A-A 26(\mathrm{p}<0.01)$, and of $C 2 * B$ with $H L A-B w 61(\mathrm{p}<0.025)$. None of these allelic combinations seem to be in linkage disequilibrium in European populations, in contrast to the fact that some allelic combinations between BF and HLA-B indicated linkage disequilibrium common to both European and Japanese populations. This finding may suggest that the BF locus is more closely linked to HLA-B locus than the $\mathrm{C} 2$ locus.

No difference in the $\mathrm{C} 2$ phenotypic distribution was observed between samples 
Table 3. Distribution of $\mathrm{C} 2$ allele frequencies in various populations.

\begin{tabular}{|c|c|c|c|c|c|}
\hline & \multirow[b]{2}{*}{$\mathrm{N}$} & \multicolumn{3}{|c|}{ C2 Alleles } & \multirow{2}{*}{ Authors } \\
\hline & & $\mathrm{C}$ & B & "A" & \\
\hline USA Caucasian & 75 & .97 & .02 & $\mathrm{AC} 1$ & Alper, 1976 \\
\hline European & 274 & .962 & .038 & 0 & Meo et al., 1977 \\
\hline Norwegian & 122 & .97 & .03 & 0 & Olaisen et al., 1978 \\
\hline West German & 289 & .965 & .035 & 0 & Dewald \& Rittner, 1979 \\
\hline Australian Caucasian & 188 & .965 & .035 & 0 & Kirk et al., 1980 \\
\hline USA Oriental & 43 & .97 & .03 & 0 & Alper, 1976 \\
\hline Japanese & 229 & .937 & .017 & 0.046 & Tokunaga et al., 1980 \\
\hline Japanese & 521 & .939 & .022 & AT $.034 \quad A^{\prime} .006$ & Tokunaga et al., $1981 \mathrm{~b}$ \\
\hline USA Negroid & 30 & .97 & .03 & 0 & Alper, 1976 \\
\hline
\end{tabular}

a "A" refers to the "acidic" variants.

Table 4. Distribution of $\mathrm{C} 2$ phenotypes and allele frequencies in Japanese (Tokunaga et al., 1981b).

\begin{tabular}{lcccc}
\hline Phenotype & Obs. No. & $\%$ & Exp. No. & $\chi^{2}$ \\
\hline C & 459 & 88.1 & 458.97 & 0.000 \\
ATC & 32 & 6.1 & 32.85 & 0.022 \\
BC & 22 & 4.2 & 21.59 & 0.008 \\
A C $^{\prime}$ & 6 & 1.2 & 5.63 & 0.024 \\
ATB & 1 & 0.2 & 0.77 & 0.069 \\
AT & 1 & 0.2 & 0.59 & 0.285 \\
B & 0 & 0 & 0.25 & 0.254 \\
ATA & 0 & 0 & 0.20 & 0.202 \\
A $^{\prime} \mathrm{C}$ & 0 & 0 & 0.13 & 0.132 \\
A $^{\prime}$ & 0 & 0 & 0.02 & 0.017 \\
\hline Total & 521 & 100.0 & 521.00 & 1.013
\end{tabular}

Allele frequencies: $\quad C 2 C=0.939 \pm 0.007$

$$
\begin{aligned}
& C 2 A T=0.034 \pm 0.006 \\
& C 2 B=0.022 \pm 0.005 \\
& C 2 A^{\prime}=0.006 \pm 0.002
\end{aligned}
$$

of IDDM patients and controls. However, in an investigation of C2 types in 120 samples of rheumatoid arthritis patients, a statistically significant deficit of C2 AT positive phenotype was observed $(\mathrm{p}<0.025)$ (unpublished data). In this respect, it is interesting that the C2 AT positive phenotype seems to have an increased C2 hemolytic activity compared to those of other phenotypes (Tokunaga et al., 1981b). 
There are three theoretical possibilities for an association between the variant complement allele and the particular disease: 1) dysfunction of the variant complement protein, 2) linkage disequilibrium with disease susceptibility gene(s) in MHC region, and 3) epistatic effects. The first possibility seems to be preferred in the recent review by Rittner and Bertrams (1981). At present, however, there seems to be no positive evidence for one of these possibilities so far as the electrophoretic variant of the human complement is concerned.

\section{C4 polymorphism}

Tokunaga et al. (1979) reported the population data of C4 polymorphism in Japanese following the two allele model. In view of the rapidly increasing literatures supporting the more recent two locus model of C4 first proposed by O'Neill et al. (1978), it seems to be premature to use this system as an established genetic marker.

In concluding, two polymorphic systems of the complement, $\mathrm{BF}$ and $\mathrm{C} 2$, are of particular importance at present as genetic markers for studies of linkage with HLA loci, disease associations and population genetics in Japanese.

Acknowledgements We are deeply indebted to Drs. T. Juji, S. Ishiba and H. Maruyama (Tokyo Women's Medical College), Dr. T. Ito (Toranomon Hospital), Drs. F. Takeuchi, A. Hashimoto, K. Matsuta, Y. Yukiyama and H. Mayeda (University of Tokyo School of Medicine) Dr. E. Tokunaga, Mr. H. Kawamata, Mr. Y. Mano and Miss Ch. Araki (Japan Red Cross Blood Center) for providing us with blood samples. We thank Miss N. Yokota and Miss A. Ishihara for excellent technical and clerical assistance.

\section{REFERENCES}

Alper, C.A., Boemisch, T., and Watson, L. 1972. Genetic polymorphism in Human glycine-rich beta-glycoprotein. J. Exp. Med. 135: 68-80.

Alper, C.A., and Rosen, F.S. 1976. Genetics of the complement system. In Advances in Human Genetics, 7 Chap. 4, Harris, H., and Hirschhorn, K., eds., Plenum Press, New York.

Alper, C.A. 1976. Inherited structural polymorphism in human C2: evidence for genetic linkage between $\mathrm{C} 2$ and BF. J. Exp. Med. 144: 1111-1115.

Dewald, G., and Rittner, C. 1979. Polymorphism of the second component of human complement (C2). Vox Sang 37: 47-54.

Farhud, D.D., Ananthakrishnan, R., and Walter, H. 1972. Association between C3 phenotypes and various diseases. Humangenetik 17: 57-60.

Harada, S., Mano, K., and Misawa, S. 1975. Genetic polymorphism of the third complement component (C3) (in Japanese), Jpn. J. Human Genet. 20; 141-146.

Hauptmann, G., Tongio, M.M., and Mayer, S. 1976. Le polymorphisme du facteur B de la properdine (C3PA, GBG, BF) et la liaison histocompatibilite complement. Rev. Fr. Transfus. Immuno-hematol. 19: 471-486.

Hobart, M.J., Vaz Guedes, M.A., and Lachmann, P.J. 1981. Polymorphism of human C5. Ann. Hum. Genet. $45: 1-4$.

Horai, S. 1976. Genetic polymorphism of human serum factor B (BF) in Japanese. Jpn. J. Human Genet. $21: 177-186$. 
Kirk, R.L., Serjeantson, S.W., Theophilus, J., Zimmet, P., Whitehouse, S., and Court, J.M. 1979. Age relationship between insulin-dependent diabetes and rare alleles of properdin factor $B$. Lancet III: 537.

Kirk, R.L., Ranford, P.R., Court, J., and Zimmet, P. 1980. Distribution of complement C'2 and C'6 types in Australian cases of diabetes mellitus. Med. J. Aust. 2: 614-615.

Lachman, P.J., and Hobart, M.J. 1978. Complement genetics in relation to HLA. Brit. Med. Bull. 34: $247-252$.

Mauff, G., Hummel, K., and Pulverer, K. 1975. Properdin factor B (glycine-rich-beta-glycoprotein or $\mathrm{C} 3$ proactivator)-polymorphism: genetic and biochemical aspects. First application to paternity cases. Z. Immun.-Forsch. 150: 327-338.

Mauff, G., Gauchel, F.D., and Hitzeroth, H.W. 1976. Polymorphism of properdin factor B in South African Negroid, Indian and Colored Populations. Hum. Genet. 33: 319-322.

Meo, T., Atkinson, J.P., Bernoco, M., Bernoco, D., and Ceppellini, R. 1977. Structural heterogeneity of $\mathrm{C} 2$ complement protein and its genetic variants in man: a new polymorphism of the HLA region. Proc. Natl. Acad. Sci. USA. 74: 1672-1675.

Mortensen, J.P., and Lamm, L.U. 1981. Quantitative differences between complement factor-B phenotypes. Immunology 42: 505.

Nishimukai, H., Sakata, K., Yamasawa, K., Hyodo, Y., Kosuge, K., Yazaki, T., and Kitamura, H. 1979. (Personal communication)

Ohayon, E., De Mouzon, A., Hauptmann, G., Klein, J., Abbal, M., Constants, J., Mayer, S., and Ducos, J. 1980. High frequency of the properdin factor Bf F1 and its linkage to HLA in French Basques. J. Immunogenet. 7: 441-445.

Olaisen, B., Teisberg, P., Gedde-Dahl, T. Jr., and Thorsby, E. 1978. Genetic polymorphism of the second component of human complement (C2). Hum. Genet. 42: 301-305.

O'Neill, G.J., Yang, S.Y., and Dupont, B. 1978. Two HLA-linked loci controlling the fourth component of human complement. Proc. Natl. Acad. Sci. USA 75: 5165-5169.

Rittner, Ch., and Bertrams, J. 1981. One the significance of C2, C4, and factor B polymorphisms in disease. Hum. Genet. 56: 235-247.

Rodriguez-Cordiba, S., Bootello, A., and Arnaiz-Villena, A. 1981. BF polymorphism and its relationship with HLA antigens in a sample of the Spanish population: high BF F1 frequencies. Tissue Antigens 17: 231-237.

Scherz, R., Pflugshaupt, R., and Butler, R. 1977. Genetic polymorphism and glycine-rich $\beta$-glycoprotein in the Swiss and Italian populations. Hum. Hered. 27: 143-146.

Stewart, G.J., Basten, A., and Kirk, R.L. 1979. Strong linkage disequilibrium between HLA-Dw2. and $\mathrm{Bf} \mathrm{S}$ in multiple selerosis and in the normal population. Tissue Antigens 14: 86-97.

Teisberg, P., and Olaisen, B. 1977. Properdin factor B (BF) polymorphism in Norway. Vox Sang. 32: 52-55.

Tokunaga, K., Horai, S., Omoto, K., Juji, T. and Nakajima, H. 1979. Genetic polymorphism of the fourth component in Japanese. Jpn. J. Human Genet. 24: 69-74.

Tokunaga, K., Omoto, K., Araki, C., and Juji, T. 1980. Genetic polymorphism of the second component of human complement (C2) in Japanese. Jpn. J. Human Genet. 25: 287-293.

Tokunaga, K., Omoto, K., Maeda, H., Juji, T., Ishiba, S., and Maruyama, H. 1981a. BF and C2 polymorphism in Japanese patients with juvenile onset diabetes mellitus: existence of a variant BF allele. Tissue Antigens 18: 365-368.

Tokunaga, K., Araki, C., Juji, T., and Omoto, K. 1981b. Genetic polymorphism of the complement C2 (in Japanese). Hum. Genet. 58: 213-216.

Tokunaga, K., Araki, C., Juji, T. and Omoto, K. 1982. Polymorphism of properdin factor B in Japanese: Description of a rare variant and data of association with HLA and C2. Hum. Genet. 60: 42-45. 